\title{
Nilai Profetis Pendidikan Islam untuk Menanggulangi Perdagangan Manusia
}

\author{
Moh. Sulhan \\ Universitas Islam Negeri Sunan Gunung Djati Bandung
}

\begin{abstract}
Trafficking creates human as commerce object by deception modus, trap, tease, fake appointment, forcing and exploitation, even the violations that insult the human. The Consortium of Indonesia Migrant Labour (KOBUMI) noted that 11.5 million from 5 million of Indonesia migrant labours are the victim. American Center for International Labor Solidarity (ACILS) report in 2003 noted that 700.000 to 1 million Indonesia migrant labours who is employable as prostitute. Many of provinces in Indonesia, such as North Sumatra, Riau, Lampung, West Java, Jakarta, Central Java, East Java, West Borneo, East Borneo, North Celebes, Bali, and The West Lesser Sundas are the sources of trafficking area. Seeing that trafficking serious problem in Indonesia, it is important to encourage the prevention by adopting many of ethic values as the reinforcement of human resource and education. Here, Islamic education is important enough to overcome anti-trafficking.
\end{abstract}

Keyword: $\quad$ trafficking, crimes against humanity, Islamic education, ethical base

\begin{abstract}
Abstrak
Trafficking menjadikan manusia sebagai objek perdagangan melalui modus penipuan, jebakan, bujuk rayu, janji palsu, pemaksaan dan eksploitasi serta bentukbentuk pelanggaran yang merendahkan martabat manusia. Konsorsium Buruh Migran Indonesia (KOBUMI) mencatat 1-1,5 juta dari 5 juta buruh migran Indonesia adalah korban. American Center for International Labor Solidarity (ACILS) report 2003 mencatat terdapat 700.000 sampai 1 juta buruh migran Indonesia yang dipekerjakan sebagai pekerjaan seksual, penghibur, dan eksploitasi kerja lainnya. Banyak propinsi di Indonesia seperti, Sumatera Utara, Riau, Lampung, Jawa Barat, Jakarta, Jawa Tengah, Jawa Timur, Kalimantan Barat, Kalimantan Timur, Sulawesi Utara, Bali dan Nusa Tenggara Barat adalah sumber daerah Trafficking. Melihat demikian serius problem Trafficking di Indonesia, dirasa sangat penting untuk mencari bentuk pencegahan melalui adopsi berbagai nilai etis bagi penguatan sumber daya manusia, penguatan kapasitas dengan pendidikan. Di sini, letak Pendidikan Islam untuk menanggulangi anti Trafficking ini menjadi penting untuk dirumuskan.
\end{abstract}

Kata kunci: trafficking, kejahatan kemanusiaan, pendidikan islam, basis etis 


\section{A. Pendahuluan}

Pendidikan adalah investasi masa depan dan sekaligus menjadi instrumen bagi penguatan kapasitas sumber daya manusia. ${ }^{1}$ Dengan pendidikan akan mendorong terciptanya beragam perkembangan dari ragam pembawaan manusia, baik dari aspek jasmani, psikologi, intelektual, spiritual, dan keterampilan. ${ }^{2}$ Pendidikan dipahami banyak ahli sebagai modal sosial, modal politik, modal ekonomi, dan modal kebudayaan. ${ }^{3}$

Demikian pentingnya posisi pendidikan, UNDP dalam Human Development Report (1990) menempatkan pendidikan sebagai salah satu aspek dari proses pengembangan manusia (Human Development) menuju tercapainya Enlarging People's Choice. Pendidikan dus, dipercaya sebagai mata air perubahan sosial, sumber ide bagi peningkatan hidup dan makna kehidupan. Pendidikan Islam yang diadopsi dari sumber-sumber ajaran pokok Islam, al-Qur'an dan Hadis memiliki kekayaan nilai yang dapat menjadi dasar profetis bagi kehidupan. Ia bukan saja dapat berfungsi sebagai dinamisator untuk menggerakkan seluruh aspek perkembangan potensi manusia, tetapi secara sinergi juga menjadi semacam lokomotif untuk penguatan kapasitas pengembangan sumber daya manusia.

Namun, kondisi yang demikian ideal dari fungsi dan makna pendidikan bagi pengembangan sumber daya manusia, sepertinya

${ }^{1}$ Berkait dengan tujuan pendidikan untuk pengembangan manusia ini UNESCO menyebut empat sasaran utama; (1) Towards a Scientific Humanism (2) For Creativity (3) Towards a Social Commitment dan (4) Towards a Complete Man. Lihat dalam Edgar Faure Et All., "Learning To Be World Of Education To Day and Tomorrow", (Paris: UNESCO, Harrahap London, 1972), hlm.146-160. Dalam konteks pengembangan kompetensi lihat Robert J. Nash, "Commitment to Competency:The New Fetishism in Teacher Education", dalam John Martin Rich (ed.), "Innovation In Education Reformers And Their Critics", (Boston, London, Sidney, Toronto, Allyn Bacon Inc., 1978). hlm. 218.

2 Lihat Zamakhsyari Dhofier, "Sumbangan Visi Islam dalam Sistem Pendidikan Nasional", dalam "Menggagas Paradigma Baru Pendidikan Demokratisasi Otonomi Civil Society Globalisasi", (Sindunata, ed.), Yogyakarta, Kanisius, cet. 5, 2004. hlm.213-229. Lihat pula Abuddin Nata, "Filsafat Pendidikan Islam", (Jakarta: Logos Wacana Ilmu, 1997).hlm.40-50.

3 J. Soedjati Djiwandono, "Globalisasi dan Pendidikan Nilai", dalam "Menggagas Paradigma Baru Pendidikan Demokratisasi Otonomi Civil Society Globalisasi”, Sindunata (ed.), (Yogyakarta: Kanisius, 2004), hlm.105. 
tak sesuai yang diharapkan. Hal ini nampak dari munculnya ragam kasus serius berupa kejahatan kemanusiaan yang biasa disebut Trafficking. ${ }^{4}$ Akibat rendahnya akses memperoleh pendidikan jutaan masyarakat Indonesia menjadi korban dari kejahatan Trafficking. Dalam konteks perkembangan kejahatan kemanusiaan yang sudah di luar ambang batas toleransi tersebut, menengahkan nilai profetis pendidikan Islam menjadi penting untuk sekedar bersumbang saran bagi upaya penanggulangan kejahatan perdagangan manusia (trafficking), khususnya perempuan dan anak-anak.

\section{B. Trafficking: Kejahatan Kemanusiaan}

Pendidikan yang rendah dari tenaga kerja Indonesia yang masih didominasi lulusan Sekolah Dasar (SD) menjadi alasan kenapa Trafficking masih subur di negara pengekspor tenaga kerja kasar (sweatshop labor) ini. Dari catatan Sri Hartati Samhadi menunjukkan fakta ini. Profil TKI sedikit banyak mewakili profil struktur ketenagakerjaan Indonesia. Dari 106,28 juta angkatan

4 Trafficking atau perdagangan manusia ditulis beragam penggunaan istilah yang tidak konsisten, berdasar rujukan yang digunakan, semisal "Trafficking", "Traffic", "Trading", atau dalam istilah yang sudah diindonesiakan Trafficking, mengacu pada kejahatan human trafficking, white slave traffic, trafficking in women and children, atau trafficking in person. Untuk menegaskan penelitian ini, penulis menggunakan pelacakan Trafficking tidak saja berdasar Konvensi "International Agreement For Supression Of The White Slave Traffic", tahun 1904, yang lebih menekankan pada "Proses Perekrutan Secara Paksa", secara khusus pada perempuan di bawah usia 18 tahun, atau terminologi "International Convention For The Supression Of The Trafficking In Women And Children", tahun 1921 yang membedakan antara "Perempuan-perempuan yang tak bersalah dan lugu" sebagai "Korban dari Penculikan dan Penipuan" dengan pekerja seks biasa. Dalam penelitian ini selain menyandingkan dengan dua pandangan diatas, penulis juga menggunakan pandangan Trafficking dalam pengertian pembantu rumah tangga, buruh ilegal-kontrak atau non kontrak, perkawinan pesanan (servile marriage), adopsi ilegal, pariwisata dan hiburan seks, pornografi, pengemis ataupun digunakan dalam aktivitas kriminal lainnya. Lihat Andri Yentriani, "Politik Perdagangan Perempuan", (Gusmiani Islah, ed.), (Yogyakarta: Galang Press, 2004), hlm.121. Bandingkan dengan hasil "International Convention for Supression of Traffic In Person and The Exploitation of the Prostitution And Others", dalam Alexander Irwan, "Perisai Perempuan: Kesepakatan International Perlindungan Perempuan", (Jakarta: LBH Apik, Forum Komunikasi LSM Perempuan dan Ford Foundation, 1999), hlm. 4. 
kerja berdasarkan Sakernas Badan Pusat Statistik (BPS) Agustus 2006, sebanyak 53,13 persen $(56,47$ juta) hanya tamat SD ke bawah. Sebanyak 20,61 persen (21,97 juta) lulusan SLTP, 20,64 persen (21,93 juta) lulusan SLTA. Sedangkan yang pernah mengenyam bangku Perguruan Tinggi hanya 5,62 persen $(5,97$ juta) di mana 2,44 juta orang yang di antaranya Diploma dan sisanya S1. Dari angkatan kerja itu, sebanyak 11,10 juta berstatus penganggur terbuka dan 95,18 juta orang bekerja. Namun dari yang bekerja ini 29,92 juta (31,44 persen) setengah menganggur. ${ }^{5}$

Kondisi ini semakin parah, melihat Human Index Development (HID) Indonesia yang rendah, di bawah urutan 110. Ini tertinggal dari Malaysia, Singapura, Thailand dan hanya lebih bagus dari Vietnam, menjadi alasan kuat kenapa Trafficking terjadi di bumi pertiwi. Apalagi problem pengangguran dan kemiskinan yang mencapai 40 juta warga Negara Indonesia yang berada di bawah garis kemiskinan dengan pendapatan di bawah $\$ 2 /$ hari versi UNDP. Tetapi, ini bukan faktor utama, karena dalam banyak kasus, ternyata korban Trafficking tak bisa baca tulis dan kurang memahami kontrak kerja yang mereka tanda tangani.

Trafficking adalah kejahatan kemanusiaan, hukum dan moral agama yang menjadikan manusia sebagai objek perdagangan melalui modus penipuan, jebakan, bujuk rayu, janji palsu, pemaksaan dan eksploitasi serta bentuk-bentuk pelanggaran yang merendahkan martabat manusia. Konsorsium Buruh Migran Indonesia (KOBUMI) mencatat 1-1,5 juta dari 5 juta buruh migran Indonesia adalah korban Trafficking. Ini mirip dengan temuan komisi VII DPR RI sebagaimana dilansir Surya Candra Ali 750.000 sampai 1 juta per tahun wanita dan anak diperdagangkan tiap tahun.

American Center For International Labor Solidarity (ACILS) report 2003 mencatat terdapat 700.000 sampai 1 juta buruh migran Indonesia yang dipekerjakan sebagai pekerjaan seksual, penghibur, dan eksploitasi kerja lainnya(ACILS-ICMC, 2004:117). ${ }^{6}$ Bukan

${ }^{5}$ Sri Hartati Samhadi, "Potret Suram TKI, Salah Siapa?", Kompas, 9 Juni 2007. hlm. 33. Laporan BAPPENAS 1997 dari sensus 1990, lulusan SD sebesar 25.154.595 jiwa, lulusan SLTP sebesar 7.966.706 jiwa, sedang lulusan Perguruan Tinggi (PT) hanya 2.505.828 jiwa saja.

${ }^{6}$ American Center For International Labor Solidarity (ACILS), Lembaga International yang peduli pada buruh migran dan menggalang kerjasama dengan berbagai NGO untuk peduli Trafficking. Salah satu kerjasama 
itu saja bentuk Trafficking yang sering ditemui di Indonesia meliputi pengiriman buruh migran perempuan, pengiriman pekerja rumah tangga (PRT), pekerja seks, pengantin pesanan dan pekerja anak. Tercatat pula beberapa kasus Trafficking perempuan untuk tujuan penyelundupan narkotika (Irianto dan Sulistiowati,2004). ${ }^{7}$ Jumlah perempuan dan anak yang menjadi korban Trafficking sudah tidak terhitung. Sulit untuk mengatakan berapa jumlah korban yang ada. Perserikatan Bangsa-Bangsa (PBB) memperkirakan bahwa sedikitnya 4 juta orang menjadi korban Trafficking setiap tahunnya. Setiap tahunnya diperkirakan 600.000-800.000 laki-laki, perempuan, dan anak-anak diperdagangkan menyeberangi perbatasan internasional. ${ }^{8}$

International Organization For Immigration (IOM) melaporkan bahwa 500.000 orang perempuan menjadi korban Trafficking di wilayah Asia Tenggara setiap tahunnya. ${ }^{9}$ American Center for International Labor Solidarity (ACILS) dan International Catholic Migration Commission (ICMC) pada 2004 mencatat propinsi di Indonesia seperti, Sumatera Utara, Riau, Lampung, Jawa Barat, Jakarta, Jawa Tengah, Jawa Timur, Kalimantan Barat, Kalimantan Timur, Sulawesi Utara, Bali dan Nusa Tenggara Barat adalah sumber daerah Trafficking. Studi LSM menyebutkan bahwa Indonesia merupakan sumber daerah Trafficking, di samping sebagai transit dan penerima perdagangan manusia. Sedikitnya diidentifikasi 10 propinsi di Indonesia dijadikan sumber, 16 propinsi di jadikan tempat transit, dan sedikitnya 12 propinsi sebagai penerima (ACILS-ICMC, 2004: $6)^{10}$

dengan International Catholic Migration Commition (ICMC), dan USAID dipublikasikan dalam buku hasil laporan kerja, "Penanggulangan Perdagangan Perempuan Dan Anak Pengalaman Sejumlah LSM Di Indonesia", (Jakarta: ACILS-ICMC, 2014), hlm. 117. lihat pula dalam "Perdagangan Perempuan dan Anak di Indonesia", Jakarta, 2003.

7 Irianto dan Sulistiowati, "Perdagangan Perempuan dalam Jaringan Pengedaran Narkotika", (Jakarta: Yayasan Obor Indonesia, Pusat Kajian Wanita UI, USAID, ACILS-ICMC, 2005), hlm.43.

${ }^{8}$ Laporan Departemen Luar Negeri AS, 14 Juni 2004.

${ }^{9}$ R. Valentina Sagala dan Ellin Rozana, "Memberantas Trafficking Perempuan Dan Anak", Bandung, Institut Perempuan, 2007.hlm.5.

10 ACILS-ICMC, "Penanggulangan Perdagangan Perempuan Dan Anak Pengalaman Sejumlah LSM Di Indonesia”, (Jakarta, USAID, 2004), hlm.VI. 
Belum ditemukan data yang paling akurat untuk jumlah perempuan dan anak korban Trafficking di Indonesia. Data yang tersedia beragam dari 74.616 orang hingga 1 juta/tahun (ACILSICMC, 2003). ${ }^{11}$ Data Resmi yang dikeluarkan Kementrian Koordinator Bidang Kesejahteraan Rakyat (2005) menunjukkan bahwa Jawa Barat, Selain Nusa Tenggara Barat dan Jawa Timur, menjadi sending area terbesar korban perdagangan perempuan dan anak.

Di Propinsi Jawa Barat, terdapat daerah-daerah pengiriman yaitu Sukabumi, Tangerang, Bekasi, Indramayu, Karawang, Bogor, Cianjur, Ciroyom, Sawangan, Depok, Cirebon, Kuningan, Bandung dan Losari-Cirebon juga diidentifikasi sebagai daerah transit. ${ }^{12}$ Data yang di laporkan Komnas Perempuan dari berbagai organisasi penyedia layanan bagi perempuan korban kekerasan menunjukkan dilema serius. Pada 2004, di antara 14.020 perempuan yang mengalami korban kekerasan sebanyak 562 kasus (4,00\%) adalah kasus Trafficking. ${ }^{13}$ Sementara data dari Komnas Perlindungan Anak yang dikeluarkan Maret 2005, jumlah anak yang menjadi korban Trafficking untuk tujuan prostitusi meningkat. Dari sekitar 200.000-300.000 (30 \%) perempuan yang dilacurkan di rumah bordil adalah anak-anak. Dan di Jawa Barat sebanyak 43,5 \% korban Trafficking anak yang dijual pada usia paling muda 14 tahun dan usia paling rawan adalah anak berusia 17 tahun. $^{14}$

Melihat demikian serius problem Trafficking di Indonesia, dirasa sangat penting untuk mencari bentuk pencegahan melalui adopsi berbagai nilai etis bagi penguatan sumber daya manusia, penguatan kapasitas dengan pendidikan. Bagaimana pesan etis Islam dapat menjadi cara dalam mencapai Enlarging People's Choice, meningkatkan ragam pilihan, sehingga beragam pengembangan fungsi, skill dan kapasitas yang memungkinkan seseorang tidak terjebak dalam praktek perdagangan orang. Di

${ }^{11}$ Lihat pula ACILS-ICMC, "Perdagangan Perempuan Dan Anak Di Indonesia", Jakarta, 2003.

${ }^{12}$ Kementrian Koordinator Bidang Kesejahteraan Rakyat RI, "Penghapusan Perdagangan Orang Di Indonesia", Jakarta 2005.

${ }^{13}$ Lihat publikasi Komnas Perempuan, "Catatan Awal Tahun 2005", (Jakarta: tp, 2005).

${ }^{14}$ R. Valentina Sagala dan Ellin Rozana, "Memberantas Trafficking Perempuan dan Anak", (Bandung: Institut Perempuan, 2007), hlm.5. 
sini, mungkin letak pendidikan Islam untuk menanggulangi anti Trafficking ini menjadi penting dirumuskan. Pertanyaan pokok yang hendak dijawab dalam studi ini adalah bagaimana nilai profetis pendidikan Islam dapat mencegah perdagangan manusia secara khusus pada anak dan perempuan?

Dalam pengertian yang umum pendidikan yang dimaksudkan di sini adalah, proses adopsi nilai secara sengaja atau sadar. ${ }^{15}$ Bukan saja dimaknai suatu kegiatan atau proses yang berhubungan dengan pembinaan yang dilakukan oleh seseorang kepada orang lain atau berupa tindakan, cara memberi pengetahuan atau pelajaran sehingga dengan usaha ini memungkinkan seseorang memiliki pengetahuan keterampilan yang menjauhkan dari jebakan Trafficking atau anti Trafficking yang secara tegas disebut dalam judul tulisan ini. ${ }^{16}$

Untuk menegaskan maksud tulisan ini, penulis menggunakan pembacaan "Trafficking" tidak saja berdasar konvensi "International Agreement for The Supression of The White Slave Traffic" tahun 1904, yang lebih menekankan pada "Proses Perekrutan secara Paksa" secara khusus kepada perempuan di bawah umur 18 tahun, atau terminologi "International Concention for The Supression of The Trafficking in Women and Children", tahun 1921, yang membedakan antara perempuan-perempuan yang tak bersalah dan lugu" sebagai "korban dari penipuan dan penculikan" dengan pekerja seks biasa. Tetapi dalam konteks penulisan ini, penulis menggunakan Trafficking tidak saja disandingkan dengan dua pandangan sebelumnya, tetapi juga untuk pembantu rumah tangga, buruh ilegal kontrak atau non kontrak, perkawinan pesanan (Servile Marriage), adopsi ilegal, pariwisata dan hiburan seks, pornografi, pengemis atau digunakan dalam aktivitas kriminal lainnya. ${ }^{17}$

Dus, secara luas perdagangan orang adalah tindakan perekrutan, pengangkutan, penampungan, pengiriman, pemindahan atau penerimaan seseorang dengan ancaman kekerasan, penggunaan kekerasan atau penculikan, penyekapan,

${ }^{15}$ Abuddin Nata, "Filsafat Pendidikan Islam I",(Jakarta: Logos Wacana Ilmu, 1997), hlm.51.

${ }^{16}$ WJS. Purwadarminta, "Kamus Umum Bahasa Indonesia", (Jakarta: Balai Pustaka, 1991), hlm.250

17 Andri Yentriani, "Politik Perdagangan Perempuan", ed. Gusmiani Islah,(Yogyakarta, Galang Press, 2004), hlm.121. 
pemalsuan, penipuan, penyalahgunaan kekerasan atau posisi rentan, penjeratan orang atau memberi bayaran atau manfaat, sehingga memperoleh persetujuan dari orang yang memegang kendali atas orang lain tersebut, baik dilakukan di dalam negara atau antar negara untuk tujuan eksploitasi atau yang mengakibatkan orang lain tereksploitasi. ${ }^{18}$

Menawarkan nilai profetis pendidikan Islam untuk penanggulangan anti Trafficking, untuk mencegah perdagangan perempuan dan anak adalah tujuan tulisan ini. Mungkin hal yang paling awal muncul ke permukaan, melihat masalah Trafficking dari sudut pandang pendidikan. Masalah Trafficking meski baru di Indonesia, tetapi sudah lama menjadi perhatian dunia internasional, bahkan hasil kerja mereka sebagian sudah dipublikasikan secara luas dan sebagian tak muncul di publik pembaca.

Valentina Sagala dan Ellin Rozana (2007) melihat Jawa Barat sebagai daerah rawan. Sukabumi, Cianjur, Kuningan, Cirebon, Subang dan Indramayu yang merupakan daerah paling subur sumber korban Trafficking di Jawa Barat. Survei di Cirebon dan Indramayu dalam tulisan ini menjadi catatan penting untuk membuka kesadaran dan sekaligus akan menjadi masukan berharga bagi para buruh migran, pengambil kebijakan dan pemerhati. Dengan menggunakan sumber langsung wanita korban Trafficking, tulisan ini mirip dengan sineas yang merekam jejak nestapa perempuan dan anak yang mengalami kekerasan dan kejahatan Trafficking.

\section{Ragam Kasus Duka: Survei dari Cirebon dan Indrama- yu}

Agamawan, di wilayah Cirebon dan Indramayu, selama ini menjadi rujukan dan sumber kekuatan masyarakat di dalam menentukan banyak hal yang berkait dengan kehidupan mereka. Bahkan dalam banyak kasus, pemimpin masyarakat, agamawan, selalu dilibatkan dalam memberikan putusan, termasuk dalam masalah tenaga kerja wanita (TKW). Bahkan sampai fatwa hukum dan pernyataan keberatan disampaikan dalam banyak kesempatan bertemu dengan masyarakatnya. Namun, hal ini tak

18 Undang-undang RI No. 21 tahun 2007 tentang Tindak Pidana Perdagangan Orang (TPPO). 
mempengaruhi atas merebaknya minat dan keinginan tenaga kerja wanita, memaksakan diri berangkat ke luar negeri. Bahkan, mulai dari rencana, pengurusan kelengkapan, berangkat, medical check up, pelaksanaan doa untuk keselamatan TKW, selalu melibatkan agamawan dan tokoh agama.

Cirebon dan Indramayu sebagai daerah religius, kota wali, sebagaimana nampak dari jumlah penduduk yang mayoritas Islam, dengan dukungan sarana ibadah, pesantren dan Kiai yang tersebar di berbagai pelosok, belum sanggup berperan banyak mengatasi problem trafficking di wilayah ini. Cirebon dengan jumlah penduduk 1.855.655 jiwa, terdapat 1.848, 558 atau 99,62\% adalah penganut Islam. Hal ini ditunjang pula sarana ibadah berupa 622 masjid, 4.905 langgar, 564 musola, 779 ulama, 321 mubalig, 1.452 khatib, 29 dai, 152 penyuluh agama. Potensi ini ditopang pula oleh 145 buah pesantren dengan 103 guru, 81 kiai, dan santri melebihi 28.526 orang, belum menjadi daya dorong strategis mengurangi dampak trafficking.

Kecenderungan malah sebaliknya angka permasalahan semakin bertambah, seperti terlihat dalam kasus-kasus perdagangan perempuan di daerah endemik semisal Kalisapu, Jadimulya, Jatimerta, Wanakaya (Cirebon Utara), Ambulu, Kali Rahayu (Losari), Kali Sari, Kali Moro, Kali Mukti (Babakan), Pati (Sedong), Buaran, Ciasem, Pangenan, Karang Suwung, Kalibangka (Astana Japura), Serang (Susukan), Panjawinangun Kulon (Gegesik), Gintung (Ciwa-ringin), dan juga di beberapa daerah di Kecamatan Cileduk, Lemah Abang (Lewi Dinding), dan sebagainya. Daerah kantong-kantong muslim dan tempat agamawan terkemuka, tetapi masalah TKW juga mengemuka.

Hal yang sama juga nampak di Indramayu. Daerah yang berada di pesisir pantai Utara ini memiliki jumlah penduduk sebesar 1.533.141 jiwa, dengan penganut Islam 1.527.650 orang. Potensi ini didukung pula oleh 92 penyuluh agama (PAH Madya), 179 (PAH Muda), 882 majelis ta'lim, 621 masjid, 74 pondok pesantren dengan 74 kiai atau pengasuh, sepertinya belum dapat berbicara banyak dalam mengurangi dampak dan penyakit sosial yang berkait dengan perdagangan perempuan (trans national international). 
Catatan Polres Indramayu pada 2003 terdapat 19 kasus trafficking (61 korban usia 14-25 tahun). ${ }^{19}$ Jumlah ini sangat kecil jika dibandingkan dengan kenyataan yang sebenarnya, karena kebanyakan korban sangat tertutup, tak melapor karena malu jika diekspos ke masyarakat luas. Daftar seperti ini menambah daftar hitam trafficking di Indonesia yang mencapai 700.000 sampai satu juta orang (2003) yang dipekerjakan sebagai pekerja seks komersial, penghibur, dan eksploitasi kerja lainnya. Daerah rawan di Indramayu misalnya di Kecamatan Karang Ampel, desa Marga Mulya (Bongas), Singaraja, Singajaya (Kec. Indramayu), Kertas Maya, Widara Sari, Juntinyuat, Lelea, Cikedung, Arahan, Cantigi dan Sukra, dan daerah terpencil yang miskin lainnya.

Karakteristik masyarakat Cirebon dan Indramayu yang sudah terbentuk sedemikian rupa, ditambah kesulitan ekonomi, banyaknya keluarga yang tidak harmonis, menikah dan cerai usia dini, serta terbatasnya lapangan kerja akan memaksa masyarakat untuk mencari penghidupan di luar daerah atau bahkan ke luar negeri. Dengan bekal pengetahuan terbatas, pendidikan dan keterampilan minim, mudah menjerumuskan mereka dalam praktek perdagangan manusia (trafficking in Women and Children) melalui beragam cara perekrutan. Kondisi seperti ini akan terus memacu masyarakat berangkat ke luar negeri. Semakin besar pula peluang dieksploitasi, khususnya wanita yang muda, cantik, dengan pengetahuan negara tujuan minim.

Banyaknya calo tenaga kerja, agen yang datang ke desa-desa, dengan mempengaruhi orang tua untuk memperkenankan anaknya dapat bekerja, meski, tanpa penjelasan jenis pekerjaannya, terkadang juga menjadi sarana praktis menyelesaikan masalah pengangguran yang tak dapat dipecahkan oleh agamawan. Kondisi kritis ini didukung pula oleh semakin besarnya tuntutan negara tujuan, seperti Arab Saudi, Hongkong, Malaysia, Singapura dan Taiwan terhadap buruh perempuan yang tidak terampil. Meningkatnya perekonomian yang lebih maju, dan kemakmuran memungkinkan kelompok menengah di negara-negara ini untuk

19 Lihat temuan Aam Azmy Al'ab, "Perdagangan Perempuan dan Anak: sebuah Praktek Neo Slavery dan Pelanggaran HAM”, Blakasuta, Fahmina Institute Cirebon, Edisi 07, 2004. hlm. 04-07. Atau Nuruzzaman, "Budaya dan Pandangan Keagamaan Masyarakat Kabupaten Cirebon dan Indramayu Terhadap Persoalan Trafficking", Laporan Penelitian, Fahmina Institute, 2005. 
mempekerjakan pembantu rumah tangga, pengasuh anak atau perawat orang lanjut usia di tengah mereka. Laporan dari Koalisi LSM menyebutkan pada tahun 1991 Malaysia hanya mengizinkan kepada 585 pembantu rumah tangga asal Indonesia. Namun pada tahun 1997, jumlah itu naik sekitar 90.000 orang. Buruh migran di Hongkong asal Indonesia juga meningkat jumlahnya, dan $70 \%$ dari total buruh migran tersebut adalah perempuan.

Indonesia menjadi sumber utama tenaga kerja murah. Laporan ACILS 2001 mencatat, ada bukti anekdot bahwa majikan dan perekrut buruh migran di Taiwan dan Hongkong lebih suka mempekerjakan buruh migran asal Indonesia, karena mereka yakin bahwa buruh migran Indonesia "cenderung kurang mengetahui hak-hak mereka, tidak bicara bahasa inggris, seperti rekan-rekan mereka dari Filipina, sehingga lebih mudah untuk dimanfaatkan" dan lebih dari itu buruh migran Indonesia "tidak terlalu sering mengajukan pengaduan dan melaporkan pelanggaran, kurang memperoleh dukungan dari kedutaan atau konsulat mereka, dan dapat digaji lebih sedikit ketimbang buruh migran dari negaranegara lain". ${ }^{20}$

Di tengah munculnya beragam kasus di wilayah Indramayu dan Cirebon, serta tingginya minat masyarakat daerah ini untuk bekerja ke luar negeri, serta kondisi negara tujuan yang kurang menghargai buruh migran asal Indonesia dan minimnya informasi negara-negara tujuan, menuntut peran lebih besar dari tokoh-tokoh agama yang dianggap memiliki kaitan penting dengan masalah yang dihadapi masyarakatnya. Paling tidak hal ini didasarkan pada beberapa alasan.

Pertama, merupakan tanggung jawab agama (wan) dalam ikut memberikan jalan pemecahan atas problem yang dihadapi umat. Karena trafficking merupakan masalah besar yang mempengaruhi kehidupan dalam arti luas, maka campur tangan agamawan menjadi sesuatu yang sangat berarti, dalam merespons dan memberikan jalan pemecahan atas problem yang dihadapi umat. Kedua, Agamawan di wilayah Indramayu dan Cirebon masih merupakan kata kunci dan tempat berkaca bagi masyarakatnya.

${ }^{20}$ Lihat dalam "Perdagangan Perempuan dan Anak di Indonesia”, Ruth Rosenberg: Editor, ICMC-ACILS, Jakarta, 2003. hlm. 45. Bandingkan dengan temuan Sri Wahyuningsih, "Dagang Manusia: Kajian Trafficking terhadap Perempuan dan Anak di Jawa Timur", Rahmat Syafaat : Editor, (Yogyakarta: Lappera Pustaka Utama, 2003). 
Posisi ini memungkinkan agamawan, Kiai, Dai, Ulama untuk melakukan intervensi melakukan banyak masukan, memberikan cara pandang baru tentang perburuan terhadap TKW yang selama ini rentan menjadi korban trafficking, orang tua, dan memaksa pengambil kebijakan melakukan sesuatu yang menguntungkan dan berpihak pada kebaikan tenaga kerja, bukan malah sebaliknya, ikut memperburuk keadaan dan ikut memeras tanpa bertanggungjawab. Ketiga, menjadi masukan, memberi pesan pendidikan Islam dalam membangun pandangan keagamaan yang peduli pada masalah trafficking, atau lebih umum dengan membangun pendidikan Islam anti perdagangan manusia.

\section{Trafficking di Mata Agamawan: Ragam Masalah dan Akar Persoalan}

Untuk memperjelas analisa masalah ini, menarik untuk melihat beragam masalah tersebut dalam bentuk catatan kasus yang terjadi di wilayah Cirebon dan Indramayu, khususnya daerah yang miskin, ekonomi terbelakang, sehingga menjadi sumber kekuatan dalam melakukan pembacaan dan analisa. Catatan kasus tersebut:

1. Penyekapan

Kasus penyekapan terjadi pada TKW asal Tulungagung Kertas Maya (Nurhayati, 20 Th). Anak ke empat dari 13 anggota keluarga ini ingin menjadi pahlawan bagi adikadiknya yang belum sekolah, dan keprihatinan akan kakaknya yang tak sekolah, sementara ibunya tukang cuci yang tak pernah mendapat JPS. Kepergian Nurhayati ke Arab Saudi membawa banyak harapan bagi diri dan keluarganya. Namun, kenyataan lain, ia disekap selama 3 bulan, dan diperkosa secara berturut-turut, akhirnya hamil. Ketika usia kehamilan 7 bulan ia dipulangkan tanpa diberi biaya. Selang sehari setelah janin lahir pada usia 7 bulan, meninggal, karena di remetremet, tidak tahan menghadapi kenyataan yang sedang dihadapi.

2. Disiksa

Cerita kekerasan dialami TKW asal Singaraja (Indramayu) yang bernama Tuniah (22 tahun). Selama 2 tahun bekerja di Abu Dabi, bukan kesenangan yang di dapat tetapi ia digebuki, disiksa sampai lukanya membekas di tubuh 
dan rambutnya habis di cabuti. Cerita kekerasan juga dialami Suneva 20 tahun, asal Singaraja Indramayu. Selama 3 tahun kerja di Riyadh, ia mengalami beragam kekerasan dan penyiksaan.

Suneva mengalami nasib menyedihkan, bukan saja dipukuli dan dianiaya, ia tak boleh salat, bahkan gajinya tak dibayar. Kekerasan juga dialami TKW asal Karang Baru (Indramayu), di Oman ia mengalami siksaan, dan tubuhnya disetrika. Menurut Kiai Sufri, yang 6 santrinya tahun ini juga jadi TKW, berusaha menolong santrinya dengan menyurati majikan, tetapi ia tak berhasil. Menurutnya "jika majikan jahat, sulit", tetapi dalam kasus yang lain ia berhasil. Misalnya kasus Nurhayati (Singaraja) yang bekerja di Riyadh, sempat diboikot gajinya, setelah datang surat Kiai, majikan jadi baik, bahkan majikannya (syeh Abdullah Hadir Badawi), sering berkomunikasi melalui surat.

3. Diperkosa

Kasus pemerkosaan TKW terjadi misalnya pada Inayah 25 tahun (Ambulu Losari). Inayah diperkirakan diperkosa di Arab Saudi. Ia pulang ke Indonesia dalam keadaan hamil, tanpa diantar siapapun. Sampai lahir bayi dari kandungannya, sampai hari ini masih belum jelas bagaimana kisahnya, siapa bapaknya, karena nikah, diperkosa atau cinta. Sumber terdekat menyebut kemungkinan di perkosa majikan. Hari ini anaknya sudah berusia 1 tahun.

Kasus serupa dialami Muhalimah 20 tahun (Ambulu Losari). Sepulang dari Arab Saudi, setelah kurang lebih 3 tahun bekerja disana, ia pulang ke Indonesia dalam keadaan Hamil. Untuk menutupi kehamilannya ia ditolong oleh temannya yang bernama Syi'ad, pergi ke desa Kaliwedi Cirebon, sampai proses kelahiran bayinya. Anak ini akhirnya di adopsi Syi'ad, dan sudah berusia 4 tahun sekarang ini. Anak tersebut bernama VENISA, artinya "diopeni syah", atau diplesetkan "Penise sapa".

4. Tidak Digaji

Kasus ini banyak terjadi pada TKW asal Indramayu dan Cirebon. Sekedar contoh, Farikha 19 tahun, asal Ambulu Losari, selama 3 tahun kerja di Arab Saudi tak digaji. PJTKI 
mencoba membantu, mengurus, tetapi tak jelas sampai hari ini.

Endah 19 tahun asal Karang Asem, 2 tahun di Arab Saudi, hanya bisa pulang saja. Biaya yang sudah dikeluarkan untuk PJTKI, biaya antar jemput dan biaya selama di penampungan tak dapat ditutupi. Bahkan sepulang dari Arab Saudi ia malah menjual tanah warisan dari ibunya.

5. Dijadikan Pelacur atau Penari

Kasus ini terjadi pada anak yang bernama Ipah (Siswi SMP Gabus, Bagau dua Indramayu. Ipah adalah anak kelas IX yang berparas cantik dan menarik. 3 tahun yang lalu, di sekolahnya kedatangan orang yang mengaku petugas dari Dinas Pariwisata, sedang mendata anak kelas III SMP untuk dijadikan duta wisata. Sekolah pun percaya, karena dilengkapi stempel, dan akan dibawa ke Jepang. Sesampai di Jakarta, ia diminta mencopot jilbabnya, kemudian didandani minim, busana seksi kemudian disuruh menemani tamu-tamu. Ia dikirim di Jepang, dibohongi dijanjikan akan dipekerjakan di restoran di Jepang, ternyata jadi penari telanjang (streaptease).

6. Dikawin di Bawah Tangan

Kasus ini dialami Sartinah 40 tahun asal Ambulu Losari. Bekerja di Malaysia kurang lebih 4 tahun. Ia pulang bawa kandungan, yang laki-laki mengantarkan ke Indonesia, setelah nikah di bawah tangan suaminya balik lagi ke Malaysia. Sekarang tanpa kabar, tanpa nafkah. Anaknya sekarang sudah menjelang 7 tahun.

Kasus serupa terjadi pada Maimunah 23 Tahun asal Ambulu Losari. Setelah ia bekerja di Riyadh, menjalin asmara dengan majikannya Abdullah Mansyur, ia dinikahi di bawah tangan. Setelah diantar pulang ke Indonesia, suaminya pergi kembali ke negara asal Arab Saudi. Sampai kandungannya lahir, dan anak menjelang besar kontak terhenti, nafkah tak ada. Ketika anaknya Sakit ia gagal memperoleh JPS, karena laki-lakinya tak terdaftar, anaknya tak terdaftar.

\section{Dibohongi PJTKI}

Kasus ini sangat banyak terjadi. Salah satunya menimpa Juju 35 tahun, calon TKW asal Jadi Mulya (Cirebon Utara). Setelah membayar 5 juta untuk ongkos pemberangkatan ke PJTKI, sampai pamitan ke tetangga, keluarga, ternyata di 
bohongi PT. Sampai hari ini tak jadi berangkat dan uangnya hilang.

Kasus serupa dialami Istri Hermanto (29 tahun) asal Gegesik Susukan, setelah nikah istrinya memaksa pergi ke Arab Saudi, karena umumnya masyarakat di situ ke Saudi, dengan berat hati ia lepaskan istrinya berangkat, namun duit sudah keluar, nasib istrinya tak jelas, ia pun tak dapat berbuat apa-apa.

8. Terjerat Cinta Haram dengan Anak Majikan

Kasus ini dituturkan oleh $\mathrm{H}$. Ihsan Karsan (Tokoh Masyarakat Karangwareng), bahwa tanggal 22/06/2005, ia baru saja melaksanakan puputan anak pungut putranya (Tatang Koswara/ Evin Suventin, Karyawan RSU Gunung Djati), atas anak yang baru lahir dari TKW asal Demak yang bernama Sulastri 34 tahun. Hasil hubungan gelap dengan anak majikan yang bernama Muflich (Riyadh). Tak ada kekerasan, atas dasar cinta kasih. Hanya tak mau mengawini. Dari 4 pembantu di Rumah majikan itu, hanya Lastri yang sering diajak ngobrol Muflich, lama-kelamaan tumbuh rasa cinta sampai berhubungan badan berkali-kali dan hamil. Karena tak mau menikahi, Sulastri pulang ke Indonesia.

9. Kehilangan Nyawa

Kasus kematian TKW bukan cerita baru, khususnya TKI di Singapura, Arab Saudi atau Korea. Kasus kehilangan dirasakan oleh Ali Jahidin (Losari). Di mana sudah 14 tahun istrinya Radliyah (37 tahun) tanpa kabar. Bermula selama kepergian istrinya pada 2 tahun pertama lancar, surat dan telepon. Namun pada tahun berikutnya hubungan dengan majikan memburuk. Radliyah ingin meminta pulang, kata majikan nanti-nanti, sampai berlarut-larut sampai 10 tahun. Sampai akhirnya majikan bilang, kalau ingin pulang-pulang sendiri saja, Radliyah akhirnya kabur. Sempat ketemu dengan tetangga asal Ambulu, suami istri, dan sempat ditampung dalam keadaan kritis. Diperkirakan ia meninggal. Sampai sekarang belum pulang, tak jelas nasib dan beritanya.

Dari temuan dan catatan kasus di atas, dapat dijelaskan secara kritis, mengapa trafficking menjadi masalah akut dan menjadi problem sosial di wilayah Cirebon dan Indramayu yang terkenal sebagai masyarakat berbasis pesantren atau malah disebut kota 
wali. Ada beberapa alasan yang dapat digunakan untuk menganalisa masalah sebagai berikut:

1. Salah Perempuan. Carut-marutnya masalah trafficking dan penipuan TKW di wilayah Cirebon dan Indramayu tak dapat dipisahkan dari objek dan subjek masalah, yaitu Perempuan. Menurut KH Aqsol Amri, masalah itu bermuara pada kesalahan TKW sendiri, "salah perempuan sendiri", juga "terkadang ada perempuan yang malah mau disuruh-suruh suami". ${ }^{21}$ Maraknya cerita duka dari TKW tak sekedar berawal dari persoalan ekonomi semata. Menurut KH Aqsol Amri, itu juga berkait dengan pergeseran moral dan sikap istri yang kurang tahan uji. Karena faktor lingkungan (TV, Masyarakat), dengan beragam informasi yang tak disaring dengan baik, sehingga apa yang menjadi keinginan istri harus terpenuhi. Kurang sedikit istri 'munclak'.

2. Bukan Masalah Agama. Dari beberapa tokoh dan Kiai yang memiliki pesantren dan banyak menerima kunjungan dan dimintai doa calon TKW/I, tak dapat memberikan penjelasan pasti tentang konsep trafficking. Tetapi sebagian tak mau bahwa trafficking disebut bukan agama. Sebagaimana di kemukakan oleh KH Chozin Nasuha, meski trafficking bukan masalah agama, karena trafficking tak ada yang mengatur, tetapi, ada persinggungan dengan agama, "karena ada perbuatan manusia". ${ }^{22}$ Sebagaimana fikih, "itu respons atas realitas berdasar kacamata keagamaan". Dalam tradisi Islam Yang ada adalah "ammat", budak-budak yang dapat dikuasai, yang dapat diperjualbelikan, bahkan di setubuhi, sebagaimana dibenarkan oleh ayat Alquran "wa mä malakat aimānukum". Sementara trafficking adalah ada tendensi menipu, memaksa orang bebas, merdeka, bukan budak, tetapi orang yang menjual jasa untuk suatu pekerjaan. Untuk itu, sebagai masalah baru (masail al waqi'iyyah al jadìdah) memang membutuhkan pendefinisian baru berdasar standar keagamaan Islam. Berdasar sifat trafficking yang menyembunyikan kehendak untuk "menipu", maka ini termasuk dalam kategori "Ghossa" atau "Ghurur" yang dilarang agama. Sabda Nabi, 'fa man

${ }^{21}$ Hidayah Cipejeh, Lemah Abang. Wawancara 22-06-2005 jam 15.10.

${ }^{22}$ Pengasuh Pesantren Dar Tauhid Arjawinangun, Dosen Pascasarjana UIN Bandung. Wawancara tanggal 29-06-2005 jam 17.30. 
ghossya falaisa minna’, barangsiapa menipu maka bukan golongan kami.

3. Patronase Kiai. Posisi Kiai dan tokoh agama di wilayah Indramayu dan Cirebon merupakan posisi sosial yang memiliki nilai tinggi. Khususnya bagi masyarakat yang selama ini banyak hidup di pedesaan dan kultur agraris, Kiai adalah sumber panutan dan kekuatan berkah. TKW yang akan ke luar negeri selalu terlibat patronase dengan Kiai, mulai dari rencana, persiapan dan pengurusan kelengkapan sampai berangkat bekerja dan pulang ke Indonesia seringkali melibatkan tokoh keagamaan sebagai sumber kekuatan magis. Berdasar tuturan $\mathrm{KH}$ Indra yang kebetulan puluhan santrinya berangkat keluar negeri "mereka mau medical check up saja, mesti kesini", saya hanya bisa bantu, "itu ambil air bak dulu ".Keyakinan ini mungkin yang mendorong pula banyak santri yang berangkat keluar negeri. ${ }^{23}$ Disini, santri yang berangkat ke luar negeri aman-aman saja, ungkap Mahrus Bilal. ${ }^{24}$ Tenaga Kerja Wanita (TKW) yang keluar negeri, tak dapat melepaskan diri dari peran strategis Kiai dan tokoh agama di daerahnya. Selain sebagai sumber kekuatan spiritual semisal doa, pengasihan, wirid keselamatan, tetapi juga tempat paling nyaman mengadukan masalah yang sedang dihadapi TKW. Sebagai contoh misalnya keberadaan KH Moh. Sufri, sangat penting bagi puluhan santrinya yang sedang di luar negeri. Keahlian komunikasi bahasa Arab lisan dan tulis, sangat membantu memecahkan masalah TKW. Ketika gaji TKW Nurhayati (Singaraja) di boikot majikannya dengan kemampuan komunikasinya dapat mencairkan masalah. ${ }^{25}$

${ }^{23}$ Pengasuh Pesantren Quranul Falah, Karang Ampel Indramayu. Wawancara 20-06-2005, jam 12.00.

${ }^{24}$ Mujahidin Saeraji, pengajar di Pesantren Roudlotul Muta'alimin (pesantren Gepolo) Singaraja Indramayu. Wawancara pada 20-06-2005, jam 14.45 .

${ }^{25}$ Sesepuh Singaraja yang terkenal dengan Aji Pengasihannya di kalangan masyarakat Indramayu. Selain Puluhan santrinya yang juga menjadi TKW di Riyadh, Bahrein, Kuwait, Qatar dan Korea, Juga menjadi rujukan TKW luar daerah Indramayu. Santrinya yang sedang di Luar negeri di antaranya Ade Suryani, Rini, Kumala, Fitria, Nurbaiti, Nurhayati, Titin, Nuraidah, Khusnul Khotimah, Muin, Pendi Agus dan Solihin, berasal dari sekitar Singaraja dan Indramayu. 
4. Budaya dan Pandangan Orang Tua pada Anak. Budaya masyarakat terkadang memberi andil besar dalam melestarikan tradisi masyarakat tertentu. Hal ini sepertinya juga nampak dari apa yang dapat disaksikan di masyarakat pesisir Indramayu dan Cirebon. Orang tua yang seharusnya menjadi pelindung anak malah berlaku terbalik, memanfaatkan anak sebagai sumber penghidupan. Masalah ini sebenarnya masalah akut yang menjadi keprihatinan luar biasa. Menurut H Tohari, kalau dalam masyarakat Islam dulu bangga dengan anak laki-laki, dan malu dengan punya anak perempuan berbeda dengan Indramayu. Menurutnya," budaya Indramayu bangga dengan anak perempuan". Budaya yang berkembang seperti ini mempengaruhi cara pandang orang tua pada anaknya, khusunya yang perempuan. ${ }^{26}$ Orang tua seringkali menganggap anak perempuan sebagai sumber investasi ekonomi orang tua. Pengakuan H Talim, AM. Membenarkan kecenderungan itu, atas alasan sosial dan ekonomi orang tua sengaja menjual anak kepada calo atau sponsor yang mudah didapat di daerah ini. Menurutnya "anak cantik jadi lahan orang tua". Cara pandang orang tua seperti ini menjadi ganjalan serius dalam merubah budaya salah kaprah tersebut. ${ }^{27}$ Kasus perceraian mencapai $80 \%$ untuk TKW, menurut H. Talim, AM. Bukan itu saja, dari 100 orang yang menikah 30 orang di antaranya di Indramayu bercerai. Orang Indramayu demikian sederhana memandang pernikahan. Bahkan orang bangga punya anak randa cilik, muda dan cantik. Sindiran RCTI, atau randa cilik turunan Indramayu, memang stigma yang mendekati kebenaran. Untuk mengurangi dampak masalah keluarga ini memang sulit. Orang tua dan anak juga harus diberi pembinaan. Menurut $\mathrm{H}$. Syakuri, faktor lemahnya pendidikan dan ekonomi, khususnya orang tua dan anak seringkali mendorong munculnya masalah ini. ${ }^{28}$

5. Tergiur Pesona Dunia. Maraknya TKW yang berangkat ke luar negeri juga dapat dilihat dari kecenderungan umum

${ }^{26}$ Komisi B. DPRD Indramayu dari PPP. Wawancara tanggal 21-062005, jam 09.45.

${ }^{27}$ Ketua KUA karang Ampel Indramayu. Wawancara pada 20-06-2005, jam 11.20.

${ }^{28}$ Depag Indramayu, pembantu Dekan Universitas Wiralodra Indramayu. Wawancara pada 20-06-2005, jam 15.00. 
wanita yang menyenangi kemewahan, harta benda dan segala macam kemewahan dunia. Banyak wanita yang berangkat keluar negeri karena iri, tak tahan melihat orang lain sukses, memiliki harta melebihi dia. Pernyataan ini dibuktikan oleh KH. Usamah Mansyur, menurutnya kecemburuan sosial lebih menjadi motivasi. Orang sudah punya sawah, berpenghasilan, karena tetangga pulang dari Arab Saudi dapat beli mobil, memperbaiki rumah, memaksa suami memberi izin ke luar negeri akhirnya berangkat ke Arab Saudi. Meminjam istilah yang di gunakan $\mathrm{KH}$ Aqsol Amri, dengan "musabaqah dunia yang sangat tinggi" Inilah pangkal segala kerusakan. ${ }^{29}$

6. Lemah Ekonomi. Lemahnya masalah ekonomi keluarga menjadi alasan paling dominan munculnya trafficking dan penipuan tenaga kerja wanita. Cara pandang keagamaan sebagaimana di jelaskan oleh $\mathrm{KH}$ Masyhuri, ini karena kemiskinan akan mendekatkan pada orang menabrak segala aturan. Orang lapar seringkali nekad melakukan hal berisiko untuk memenuhi kebutuhan ekonomi, bahkan sampai melakukan kejahatan atau bahkan lebih ekstrem menjual diri. $^{30}$

7. Lemah Skill dan Pendidikan. Lemahnya kompetensi dan keterampilan atau pendidikan tenaga kerja wanita seringkali menjadi masalah serius di negara tujuan. Masalah ini kurang di perhatikan. Menurut KH Hasanuddin, kurangnya lapangan pekerjaan, mendorong orang memaksa ke luar negeri. ${ }^{31}$ Menurutnya, "80 \% TKW yang berangkat keluar negeri tak menguasai bahasa dan tak memahami budaya tujuan". Meski ini merupakan persyaratan utama untuk menjamin keselamatan TKW, jarang mendapat perhatian, "orang tetap memaksa berangkat, berebut persaingan". Masalah ini menjadi akar persoalan yang menjadikan kekerasan pada Tenaga Kerja wanita (TKW) di negara tujuan.

8. Korupsi. Masalah merebaknya kasus dan praktek korupsi dianggap ikut mempersubur aliran tenaga kerja keluar negeri,

${ }^{29}$ Pengasuh Pesantren An Nasuha, Babakan Cirebon. Wawancara pada 22-06-2005 jam 11.38.

${ }^{30}$ Masyhuri, Dosen Unwir Indramayu, Hakim pengadilan Agama Indramayu. Wawancara di rumahnya pada 20-06-2005 jam 13.00.

${ }^{31}$ Pimpinan Pesantren Al Munawaroh Sedong. Wawancara tanggal 2206-2005, jam 09.00. 
dan praktik trafficking akan terus tumbuh. Menanggapi kondisi ini, sempat menjadi keprihatinan agamawan. Menurut $\mathrm{KH}$ Masyhuri, dilihat dari kemampuan negara Indonesia itu kaya, besar, banyak pulau, tetapi kenapa tak dapat memakmurkan rakyatnya. Malaysia itu negara kecil, tetapi nomor 2 penghasil kelapa sawit terbesar di dunia. Padahal wilayahnya hanya sebesar pulau Jawa. Indonesia luas, kok tak bisa, kesimpulannya "orangnya yang tak jujur". Program baik, niat baik, jika orangnya tak baik bisa mengacaukan semua. Jika ada lapangan kerja, tak akan ada TKW ke luar negeri. Uang korupsi dan semacamnya itu cukup untuk membiayai rakyat, sehingga tak usah berbondong-bondong ke luar negeri.

9. Minimnya Pengetahuan dan Perbedaan Budaya Negara Tujuan. Banyak TKW berangkat ke negara tujuan tanpa pemahaman memadai mengenai budaya masyarakat negara yang dituju. Ini dapat menjadi masalah serius yang kurang menguntungkan. Arab Saudi Misalnya meski, dalam benak TKW negara Islam, Kota Suci, sebenarnya berbeda jauh dalam perilaku masyarakatnya. KH A. Karim menyebutkan "seblesak-blesak orang Indonesia lebih baik daripada orang Arab (Seburuk-buruk orang Indonesia lebih baik dari pada orang Arab)". ${ }^{32}$ Budaya masyarakat Arab itu sangat kental dengan arogansi. Karena merasa lebih mulia orang Arab memiliki "mental memperbudak" menurut KH Masyhuri. Parahnya, di Arab TKW masih diserupakan dengan "ammat" budak yang dapat bebas diperlakukan. Membayar 7000 real ke PJTKI dianggap seperti beli. Menurut KH Syakur Yasin,MA, sebaiknya TKW dihentikan sebelum ada kejelasan status TKW, jam kerja, cuti dan besaran gaji. Kecenderungan umum TKW Indonesia hanya dihargai 100 dolar sedang dari Philipina sebesar 200 dolar karena dipengaruhi banyak persepsi dan budaya. ${ }^{33}$

10. Suami Tak Bertanggungjawab. Meski ada unsur kewajiban istri atas suami, bagi TKW yang sudah menikah, atas alasan apapun meninggalkan suami, agama melarang. Ada unsur meninggalkan ini agama melarang meski ada izin. Namun,

${ }^{32}$ Pimpinan Pesantren Al Falah Kertas Maya. Wawancara tanggal 2106-2005, jam 12.55.

${ }^{33}$ Pengasuh Pesantren Candang Pinggan Indramayu. Wawancara tanggal 21-06-2005, jam 15.20. 
Banyaknya TKW yang berangkat ke luar negeri juga di pengaruhi oleh posisi suami yang kurang bertanggungjawab. Kewajiban suami adalah melindungi istri, memberi nafkah, ternyata suami tak memenuhi ini, dan itu yang menjadi salah satu penyebab munculnya permasalahan ini.

Menanggapi maraknya kasus trafficking yang mengorbankan banyak perempuan di wilayah Indramayu dan Cirebon, seperti digambarkan dalam catatan kasus di mana TKW mengalami berbagai korban kekerasan seperi, penyekapan, penyiksaan, pemerkosaan, tak diberi gaji, dijadikan pelacur atau penghibur, dikawin bawah tangan, dibohongi PJTKI, terjerat cinta haram sampai pada penghilangan nyawa, menjadi keprihatinan agamawan, Kiai dan tokoh masyarakat di wilayah ini. Usahausaha yang dilakukan untuk merespons masalah ini sekedar disampaikan nasehat atau peringatan secara etis (ethical review), misalnya melalui pesan-pesan melalui ceramah agama. Menurut KH. Usamah Masyur, dalam setiap pertemuan siswa dan orang tua siswa (haflah akhír sanah), meminta pada wali santri untuk tidak 'mengirimkan anaknya menjadi TKW', ia senantiasa menegaskan tak pernah setuju perempuan berangakat ke luar negeri. Perempuan selalu jadi tumpuan tindak kekerasan.

Beberapa harapan dari agamawan wilayah Indramayu dan Cirebon berkait maraknya kasus trafficking di antaranya dikemukakan oleh KH. Syakur Yasin. Kepada pemerintah harusnya memperjelas status tujuan negara yang menerima TKW Indonesia (MOU), mengenai status TKW, gaji, masa cuti, dan jam kerja. Jika tak bisa sebaiknya hentikan seluruh pengiriman TKW. TKW harus buruh, bukan budak, diasramakan tidak serumah dengan majikan dengan jam kerja 8 jam. H Syakuri mengharapkan TKW yang akan berangkat ke luar negeri dibekali dengan keterampilan, pengetahuan memadai dan bahasa negara tujuan. Selanjutnya ia mengharap TKW hendaknya disertai dengan mahram, jika sudah menikah sebaiknya bersama-sama dengan suaminya. Orang tua jangan terlalu memaksa anak berangkat keluar negeri, sebaiknya diberi pendidikan yang cukup, agar dapat mandiri. Jika sudah bersuami, masalah nafkah tanggungjawab suami. Hal sama juga disampaikan oleh $\mathrm{KH}$ Indra, agar pemerintah dapat membekali keterampilan, dan wawasan agama, menertibkan penyalur, agen atau PT yang liar dan ilegal yang sering menjebloskan TKW dalam penderitaan. 
Sementara itu, perlu penyadaran dan pembentukan lembaga pakar yang dapat menyiapkan TKW. Jika mental sudah siap, kerja tujuan negara jelas, gaji jelas, tinggal dilatih, dan yang sudah siap diberangkatkan, harap HJ. Sri Umi Maziyah. Tak sejalan dengan pikiran TKW yang ke luar negeri, KH Hasanuddin, memilih pada peran pemerintah untuk membuka pelatihan-pelatihan, membuka lapangan kerja, dorong kreativitas warga. Jika berjalan anak bangsa ini tak usah ke luar negeri, di sini saja bisa hidup. Pemerintah saatnya menetapkan undang-undang yang dapat dilaksanakan dan melindungi hak-hak dan keselamatan TKW. Persyaratan mengenai TKW dipersyaratkan dengan kualifikasi tertentu, pengalaman tertentu, agar di negara tujuan tak mengalami kebingungan. Transmigrasi, jika bisa dihidupkan akan menampung jumlah besar pengangguran, asal dikelola dengan baik dan diperhatikan. Negara dikelola rakyat, warga negara tak perlu memakmurkan negara lain. Keberkahan ada di tanah sendiri.

Pemerintah, harap KH Wawan Arwani, memberikan jaminan perlindungan pada seluruh TKW, jangan mengabaikan pahlawan devisa. Informasi lapangan kerja di negara tujuan harus utuh, jangan asal berangkat. TKW mulai belajar menyerap informasi yang sebanyak-banyaknya, jika bertetapan hati bekerja di luar negeri. Sementara lembaga pendamping dapat memberikan penyuluhan, sosialisasi dan penyadaran.

\section{E. Pendidikan Islam: Nilai Profetis untuk Melawan Keja- hatan Kemanusiaan}

Islam secara khusus memiliki penghargaan atas manusia. Tak diperkenankan atas alasan apapun manusia satu memperdayai manusia lainnya. Islam memerintahkan agar ada proses saling melindungi. Menyelamatkan manusia satu itu bahkan diserupakan seolah-olah telah menyelamatkan manusia secara keseluruhan. Dalam konteks kejahatan traffiking penting untuk disampaikan tentang penghargaan pendidikan Islam pada Kemanusiaan. Secara umum penghargaan Pendidikan Islam sebagai berikut:

1. Islam menghargai atau menghormati manusia. Manusia sebagai makhluk dan hamba Allah ditempatkan sangat terhormat dalam kehidupan di dunia ini,dimuliakan Allah, diberi Rezeki, diberi fasilitas hidup dan diutamakan dari makhluk yang lain. Sangat tegas disebut dalam al-Qur'an. (Q.S. al-Isra 70, al-Anbiya 21: 107, al-Baqarah 112 dan al- A'raf 7: 56) 
2. Islam menghindarkan manusia dari kondisi sosial yang timpang. Islam mengajarkan hidup yang positif, tak boleh ada kezaliman, penipuan dan tindakan yang merugikan (Q.S. anNisa. 4: 75, al-Qashas 5).

3. Islam melarang berbuat zalim. Islam mencela orang yang menjadikan anak perempuan sebagai pelacur, dihisap dan diperlakukan tak manusiawi (Q.S. al-Syura 42, al-Nur 33).

4. Perintah saling tolong menolong (Q.S. al-Maidah 2, at-Tahrim 6). Demikian banyak rambu-rambu etis yang diberikan oleh al-Qur'an sebagai basis etis membangun persaudaraan dan pergaulan dalam kehidupan ini. Tujuan yang paling utama dalam konteks kehidupan adalah untuk menjaga keseimbangan sosial, ketertiban dan menghindarkan patologi, semisal memperdayai sesama seperti kasus traffiking.

Dalam berbagai pesan moral-etis al-Qur'an disebut Fazlur Rahman sebagai sarana untuk menyusun keamanan ontologis manusia dan sekaligus bekal menyusun struktur msyarakat yang adil, sejahtera didasarkan pada etika. Ini sering diulang-ulang dan tidak lain dalam rangka menjamin keteraturan dan menjauhi kemungkaran. ${ }^{34}$ Hadis Nabi dan al-Qur'an menjadi basis etis dari pendidikan Islam untuk membimbing manusia; 1) berbuat baik, 2) memberi manfaat pada sesama, 3) saling membantu, 4) tidak menipu, 5) pelarangan kekerasan dan kezaliman. Berdasar ajaran dan nilai Islam di atas Trafficking harus secepatnya ditangani dengan baik, selain merupakan kejahatan moral, kejahatan kemanusiaan dan juga kejahatan hukum.

Rambu-rambu ini penting mengingat terlalu banyak pelanggaran hukum yang dilanggarnya. Pelanggaran atas; (1) UUD 1945 pasal 27 ayat 2 Tentang: Tiap warga negara berhak atas pekerjaan dan penghidupan yang layak. Pasal $28 \mathrm{D}$ ayat 2 , Tiap warga negara berhak untuk bekerja, mendapat imbalan layak dan perlakuan adil dalam hubungan kerja.(2) KUHP pasal 324-337 tentang perbudaan dan penghambaan dengan ancaman penjara 5-15 tahun/denda 60-300 juta. (3). UU no 23/2002 tentang perlindungan anak, (4). UU no 23/2004 tentang Penghapusan Kekerasan dalam

34 Q.S. al-Isra17: 70; al-Anbiya, 21: 107; al-Baqarah, 2: 112; alSyura/42: 42; dan hadis "Aku wasiatkan kepada kalian, agar berbuat baik kepada perempuan, karena mereka sering menjadi sasaran pelecehan di antara kalian. Padahal, kalian berkewajiban untuk berbuat baik kepada mereka" (HR. al-Turmudzi). 
Rumah Tangga (KDRT), (5) UU no 39/2004 tentang Penempatan dan Perlindungan TKI di luar negeri, (6) Convention on the Elimination Discrimination Against Women (CEDAW), dan Universal Declaration of Human Right (UDHR), dan (7) UU tentang Tindak Pidana Perdagangan Orang (TPPO). Untuk menanggulangi kejahatan ini, juga selain memper-timbangkan perlunya memperhatikan pesan etis Islam, secara realistis diikuti dengan upaya mengetahui akar masalah dari trafficking, sehingga penyelesaian dapat berjalan secara holistik dan tidak parsial.

\section{F. Penutup}

Masalah trafficking sudah demikian akut, dan hampir melibatkan korban dari berbagai lapisan masyarakat Indonesia. Pesan profetis Pendidikan Islam secara sinergis akan menjadi input bagi kontribusi ethical review perilaku kejahatan kemanusiaan atau Trafficking. Ini nilai yang penting untuk menjadi ramburambu agar orang tidak berbuat aniaya pada diri atau orang lain. Apa lagi sampai menjual manusia. Namun demikian, melihat kompleksitas masalah Trafficking, upaya penyelesaian harus juga menyeluruh. Tak bisa sepotong-potong. Oleh karenanya, perlu kiranya ditegaskan di sini sebagai catatan; Pertama, mengenali sumber masalah. Jika masalahnya kemiskinan dan pendidikan rendah, maka perlu adanya kebijakan yang dapat mendorong tersedianya sarana pendidikan, membuka lapangan pekerjaan dll.

Dan Kaidah Fiqh "Kebijakan pemerintah atas rakyatnya didasarkan atas kepentingan dan kesejahteraan rakyatnya. Kedua, mempersiapkan regulasi yang memihak pada pekerja, khususnya wanita yang rawan korban Trafficking: mendesak secara serius implementasi Keputusan Presiden RI no 88/2002 tentang RAN P3A (Rencana Aksi Nasional Penghapusan Perdagangan Perempuan dan Anak), Mendesak DPR RI untuk memback-up penerapan dan pelaksanaan keras sangsi dan regulasi dalam Undang-Undang Tindak Pidana Perdagangan Orang (UUTPPO). Ketiga, mendorong partisipasi agamawan untuk terlibat penanggulangan trafficking melalui khutbah, pengajian atau fatwa. Misalnya (Fatwa Pengurus Besar Nahdlatul Ulama (PBNU) tentang Pengharaman Perdagangan Manusia (Trafficking). Dengan cara ini pesan profetis Pendidikan Islam secara sinergis akan menjadi input bagi kontribusi ethical review perilaku kejahatan kemanusiaan atau Trafficking. 


\section{Kepustakaan}

ACILS-ICMC. 2003. "Perdagangan Perempuan dan Anak di Indonesia". (Ruth Rosenberg. ed.). Jakarta: ICMC-ACILS.

ACILS-ICMC. 2004. "Penanggulangan Perdagangan Perempuan dan Anak Pengalamam Sejumlah LSM di Indonesia". Jakarta: ACILS-ICMC. USAID.

Al'ab, Aam Azmy. 2004. "Perdagangan Perempuan dan Anak: sebuah Praktek Neo Slavery dan Pelanggaran HAM". Blakasuta.

Fahmina Institute Cirebon, Edisi 07.

Djiwandono, J. Soedjati. 2004. "Globalisasi dan Pendidikan Nilai". dalam "Menggagas Paradigma Baru Pendidikan Demokratisasi Otonomi Civil Society Globalisasi". (Sindunata. ed.). Yogyakarta: Kanisius. cet. 5.

Dhofier, Zamakhsyari. 2004. "Sumbangan Visi Islam dalam Sistem Pendidikan Nasional". dalam "Menggagas Paradigma Baru Pendidikan Demokratisasi Otonomi Civil Society Globalisasi”. (Sindunata. ed.). Yogyakarta: Kanisius, cet. 5.

Departemen Sosial RI. 2004."Pedoman Pencegahan Trafficking Anak dan Rehabilitasi Sosial Anak Korban Trafficking”. Direktorat Jendral Pelayanan dan Rehabilitasi Sosial. Direktorat Bina Pelayanan Sosial Anak

Faure, Edgar.. et all. 1972. "Learning To Be World Of Education To Day and Tomorrow". Paris: UNESCO, Harrahap London.

Izutsu, Toshihiko.1996."Ethico-Religious Concepts in the Quran". Montreal: MC Gill University Press.

Irwan, Alexander. 1999. "Perisai Perempuan: Kesepakatan International Perlindungan Perempuan". Jakarta. LBH Apik. Forum Komunikasi LSM Perempuan dan Ford Foundation.

Irianto dan Sulistiowati. 2005."Perdagangan Perempuan dalam Jaringan Pengedaran Narkotika”. Jakarta. Yayasan Obor Indonesia. Pusat Kajian Wanita UI. USAID. ACILS-ICMC.

Kementrian Koordinator Bidang Kesejahteraan Rakyat RI. 2005. "Penghapusan Perdagangan Orang Di Indonesia". Jakarta.

Komnas Perempuan. 2005. “Catatan Awal Tahun 2005”. Jakarta. Laporan Departemen Luar Negeri AS. 14 Juni 2004. 
Nash, Robert J. 1978. "Commitment to Competency:The New Fetishism in Teacher Education". dalam John Martin Rich (ed.). "Innova-tion In Education Reformers And Their Critics". edisi 3. Boston, London, Sidney, Toronto: Allyn Bacon Inc.

Nata, Abuddin. 1997. "Filsafat Pendidikan Islam". Jakarta: Logos Wacana Ilmu.

Nuruzzaman. 2005. "Budaya dan Pandangan Keagamaan Masyarakat Kabupaten Cirebon dan Indramayu Terhadap Persoalan Traffick-ing". Laporan Penelitian. Fahmina Institute.

Samhadi, Sri Hartati. 2007. "Potret Suram TKI. Salah Siapa?". Kompas, 9 Juni 2007.

O'Connor, DJ. 1957. “An Introduction to the Philosophy of Education". London: Routhlegde and Kegan Paul.

Purwadarminta, WJS. 1991. "Kamus Umum Bahasa Indonesia". Jakarta: Balai Pustaka.

Qodir. Faqihuddin Abdul. dkk. 2006. "Fiqih Anti Trafficking. Jogyakarta: Pustaka Pesantren.

Sagala, R. Valentina dan Rozana. Ellin. 2007. "Memberantas Trafficking Perempuan Dan Anak". Bandung: Institut Perempuan.

Undang-undang RI No. 21 tahun 2007 tentang Tindak Pidana Perdagangan Orang (TPPO).

Wahyuningsih. Sri. 2003. "Dagang Manusia: Kajian Trafficking terhadap Perempuan dan Anak di Jawa Timur". Rahmat Syafaat : Editor. Yogyakarta: Lappera Pustaka Utama.

Yentriani. Andri. 2004. "Politik Perdagangan Perempuan". (Islah. Gusmiani. ed.). Yogyakarta: Galang Press. 
